\title{
ICDS in India: Policy, Design and Delivery Issues
}

\author{
Naresh C. Saxena and Nisha Srivastava
}

\begin{abstract}
India's excellent economic growth in the last two decades has made little impact on the nutrition levels of its children. Its main intervention, the Integrated Child Development Services (ICDS) programme, has not yet succeeded in reducing child malnutrition. The programme is reaching less than one-third of all children. ICDS also faces substantial operational challenges, such as lack of monitoring. The article discusses the flaws in the design of ICDS, and suggests practical measures to improve its implementation. It argues that the basic nature of the ICDS scheme should be changed from centre-based to outreach-based, with a focus on children under two years old. The emphasis should be on the difficult tasks of changing childrearing practices, and the control and treatment of infectious diseases. The article argues against provision of packaged food, as this is unpopular with young children and has led to corruption.
\end{abstract}

\section{Introduction}

In the decade and a half that India has embraced economic reform, a problem has haunted the country and vexed policymakers: India's excellent growth has made little positive impact on the nutrition of its children. Undernutrition rates are not only high, but stubbornly persistent and in the last eight years, they have only come down by about 1 per cent. It is uncertain whether the country will meet the MDG targets, or its own ambitious targets set out in the 11 th Plan.

The Government's response to this challenge is the Integrated Child Development Services (ICDS). Launched in 1975 as 'the foremost symbol of India's commitment to her children', ICDS provides a package of six basic services; pre-school education, supplementary nutrition, immunisation, health check-ups, referral services and nutrition and health education. These are provided at the Anganwadi Centre (AWG). The anganwadi worker (AWW) is the pivot of the programme, and its success largely depends on her. While the scale of the programme is impressive, its performance falls short of expectations.

This article examines the performance of the ICDS on the basis of evidence from NFHS-3, and discusses design, policy and delivery issues that will make the programme achieve its objectives.

\section{An assessment of the ICDS \\ 2.1 Coverage}

The NFHS-3 data show that 81 per cent of children under six years of age were living in an area served by an AWC. This is still far short of the 100 per cent coverage that should have been achieved after 35 years. Accessibility is important, and in a study (WFP 2008) covering four of the poorest states, 88 per cent of all respondents gave distance from the $\mathrm{AWC}$ as a reason for not using the $\mathrm{AWC}$.

\subsection{Utilisation of services}

While coverage is important, it is not enough. Not much is achieved if an AWG exists, but remains closed most of the time. The findings of the NFHS-3 are a damning indictment of the programme, and are summarised in Table 1.

Only 32.9 per cent of children (living in an area covered by an AWC) used any AWC services in the 12 preceding months. The programme provides supplementary food for children below the age of six and pregnant and nursing mothers for 300 days/year. Only 26.5 per cent of children had received Supplementary Nutrition (SN) and 


$\begin{array}{ll}\text { Availed any service from AWC } & 32.9 \\ \text { Supplementary nutrition } & 73.5 \\ \text { Not at all } & 26.5 \\ \text { Sometimes } & 11.9 \\ \text { Almost daily } & 80 \\ \text { Immunisation (not even one antigen) } & 17.8 \\ \text { Monthly health check-up } & 18.2 \\ \text { Regular weighing } & 22.8 \\ \text { Pre-school activities } & \\ \text { Children whose mothers received supplementary food } & 20.5 \\ \text { During pregnancy } & 16.5 \\ \text { While breast-feeding } & \\ \text { Children whose mothers received a health check-up } & 12.3 \\ \quad \text { During pregnancy } & 8.5 \\ \text { While breast-feeding } & \end{array}$

Note This data relates only to children $<6$ years who live in an area covered by an AWC.

only 12 per cent regularly received it. A total of 21 per cent of pregnant women and 17 per cent of lactating mothers received supplementary food. The utilisation of other components of the programme is equally dismal. Only 20 per cent of children were immunised in the AWG and 82 per cent of children had never had a health check.

AWCs are equipped with medical kits and AWWs are trained to deal with day-to-day ailments, but only 0.1 per cent $(0.2$ per cent in the poorest group) said they went to the AWC when a family member was sick. Some 62.5 per cent of households went to a private provider and 36.5 per cent to a government centre.

\subsection{Utilisation of AWC services in selected states}

The utilisation of AWC services is low in all states, but surprisingly the AWCs perform better in some of the poorest states, such as Orissa and Chhattisgarh.

Table 2 shows that the proportion of children who received services from an AWC was twice as high as the national average in Chhattisgarh and Orissa. Table 3 shows that these two states did equally well in providing services to pregnant and nursing mothers. Judging the performance of AWCis on the basis of so many components can be complicated. We therefore constructed an index of performance. States are first ranked by performance on each component of the programme; the ranks are then aggregated to give a composite index of AWG performance. ${ }^{2}$

Does improving the performance of the AWC impact on nutritional status? Table 4 ranks states by poverty ratio, performance on $\mathrm{AWC}$ and improvement in child nutrition. There is no linear or straightforward relationship between performance on AWG and outcomes, but two states stand out, Chhattisgarh and Orissa. They are among the poorest states, but they are the best ICDS performers and most successful at reducing undernutrition. During 1998-2005, the percentage of underweight children declined from 54 per cent to 44 per cent in Orissa and from 61 per cent to 52 per cent in Chhattisgarh.

What accounts for Chhattisgarh's performance? Reports suggest that social mobilisation through the Mitanin programme launched in 2002, has contributed to bringing down malnutrition (Garg 2006; Sundararaman 2006). The mitanin (meaning a friend) is chosen by the local community and is trained and supported by a block training team, an auxiliary nurse midwife (ANM) and the AWW. She provides the following services: (1) health education, (2) first aid and over-the-counter drugs, (3) treatment for minor ailments, (4) referral advice, and (5) leadership in mobilising the community. There are over 60,000 mitanins. 
Table 2 Indicators of utilisation of ICDS services by children

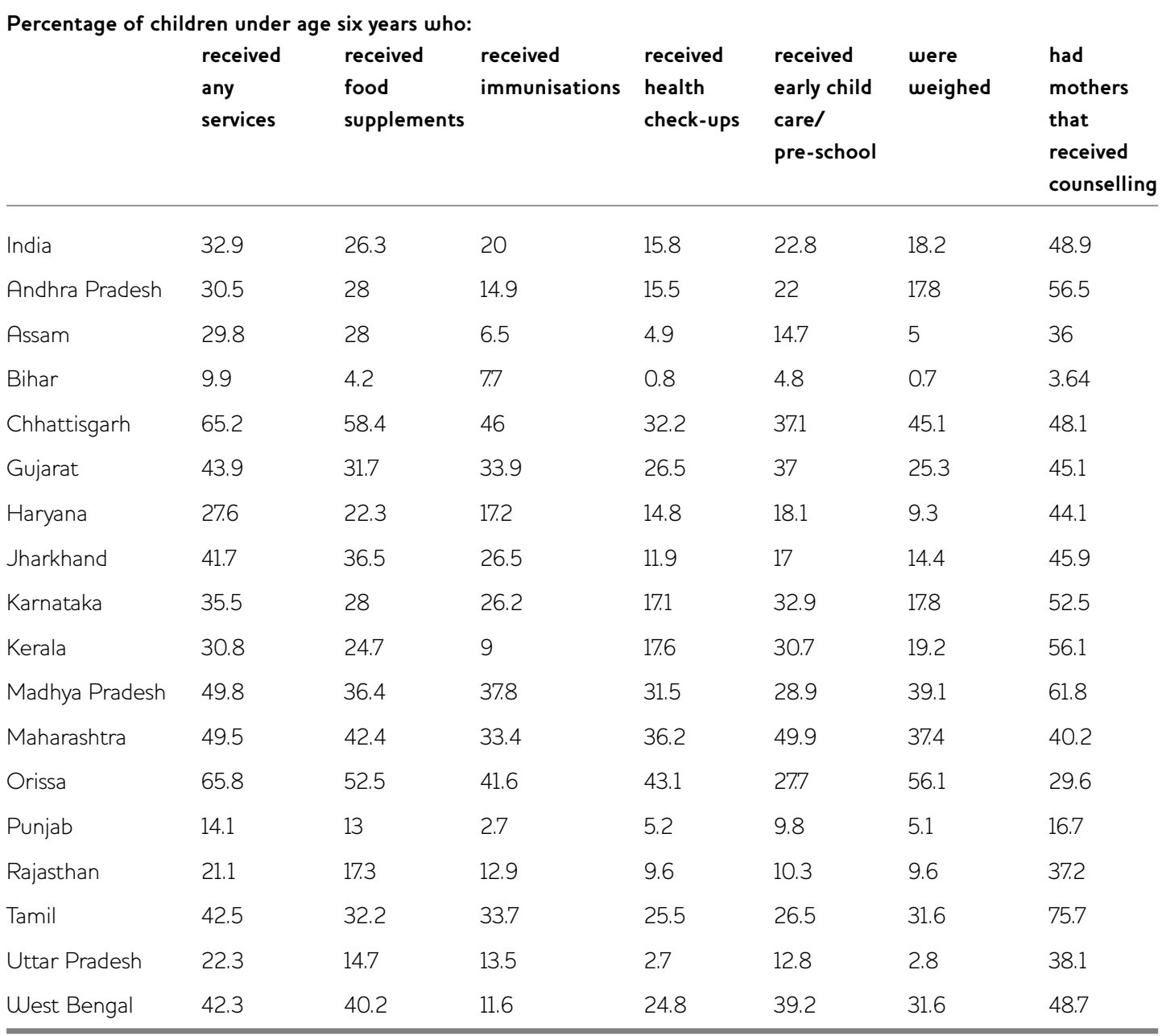

The Government of Orissa (GoO) has developed a comprehensive Health and Nutrition Sector Plan, which aligns the resources of the Government of India (GoI) and development partners' to complement Orissa's efforts to meet its priorities and address shortcomings in both public and private provision for nutrition and health. It has also set up a Nutrition Council that includes experts and professionals from DFID, UNICEF, CARE, World Bank and civil society. It has launched several innovative programmes such as: the Nutrition and Health Day in collaboration with CARE; the positive-deviance approach implemented in partnership with UNICEF; the change-agent approach on the lines of the Mitanin experiment of Ghhattisgarh to identify and target excluded populations.
We used an OLS regression model to analyse NFHS data to see if AWC services played a role in reducing malnutrition. The results show that overall, the ICDS has contributed to lowering undernutrition.

1 The most important result is that AWCs make a difference. Results show that children who are in areas not covered by an AWC are significantly more undernourished than those in areas covered by an AWC that has been in existence for more than five years.

2 Children seen by an AWW in the past three months are likely to be significantly more undernourished than those who were not seen, suggesting that mothers have faith in AWWs and take their children to her when there is a problem. 
Table 3 Indicators of women's utilisation of ICDS services by state

\begin{tabular}{|c|c|c|c|c|c|c|}
\hline & $\begin{array}{l}\text { Perce } \\
\text { receiv } \\
\text { during }\end{array}$ & $\begin{array}{l}\text { children u } \\
\text { ollowing, f } \\
\text { ncy }\end{array}$ & $\begin{array}{l}\text { mothers } \\
\text { an AWC }\end{array}$ & $\begin{array}{l}\text { Perce } \\
\text { receiv } \\
\text { while }\end{array}$ & $\begin{array}{l}\text { children w } \\
\text { ollowing, fr } \\
\text { eeding }\end{array}$ & $\begin{array}{l}\text { e mothers } \\
\text { an AWC }\end{array}$ \\
\hline & Suppl & y Health & Health \& & Suppl & y Health & Health \& \\
\hline & food & check-up & $\begin{array}{l}\text { nutrition } \\
\text { education }\end{array}$ & food & check-up & $\begin{array}{l}\text { nutrition } \\
\text { education }\end{array}$ \\
\hline India & 20.5 & 12.3 & 10.9 & 16.5 & 8.5 & 8.3 \\
\hline Andhra Pradesh & 22.9 & 13.1 & 15.5 & 17.4 & 11.4 & 13 \\
\hline Assam & 12.7 & 2.1 & 1.7 & 12.7 & 1.9 & 2 \\
\hline Bihar & 0.6 & 0.3 & 0.2 & 0.6 & 0.3 & 0.3 \\
\hline Chhattisgarh & 64.1 & 43.6 & 30.2 & 63.2 & 26.6 & 24.6 \\
\hline Gujarat & 19.1 & 14.9 & 13.5 & 12.1 & 8 & 8.4 \\
\hline Haryana & 11 & 6.3 & 4.6 & 6.1 & 2.9 & 2.7 \\
\hline Jharkhand & 34.7 & 13.6 & 13.4 & 35.9 & 9.5 & 12.2 \\
\hline Karnataka & 30.3 & 16.9 & 20.8 & 18.4 & 10.5 & 12.5 \\
\hline Kerala & 15.8 & 9.6 & 10.4 & 10.5 & 5 & 6.8 \\
\hline Madhya Pradesh & 31 & 25.1 & 21.7 & 27 & 18.3 & 17.5 \\
\hline Maharashtra & 25.8 & 20.7 & 13.4 & 17.5 & 13 & 10.4 \\
\hline Orissa & 44.6 & 41.8 & 23 & 39.8 & 28.3 & 16.7 \\
\hline Punjab & 7.5 & 3.2 & 3.2 & 5.5 & 2 & 2.5 \\
\hline Rajasthan & 17 & 10.2 & 4.3 & 12.4 & 7.1 & 3.2 \\
\hline Tamil Nadu & 50.4 & 35.6 & 36.3 & 42.5 & 29 & 29.1 \\
\hline Uttar Pradesh & 9.6 & 1.8 & 1.3 & 7 & 0.6 & 0.7 \\
\hline West Bengal & 23.1 & 9.7 & 14.3 & 19.3 & 7.7 & 10.8 \\
\hline
\end{tabular}

Note relates to children $<6$ years of age and living in an area covered by an AWC.

3 The only variable that is highly significant and has a positive impact on nutritional status is if the child received early childcare at the AWC. Maharashtra (50 per cent), West Bengal (39 per cent) and Chhattisgarh (37 per cent) reported the highest percentage of children receiving early childcare/pre-school. These states are among the top five performers in reducing undernutrition. This strengthens the argument for focusing on these services.

4 Children who were measured at an AWC were significantly more undernourished. This suggests that these children were measured because they were undernourished.
5 A child who had diarrhoea or fever/cough and was treated at an AWC was likely to be less undernourished than a child who was not treated or a child who was treated elsewhere.

Critics argue that if after 35 years, the ICDS has not shown results it should be wound up. Our results show that even in areas that have the worst chronic poverty, there is hope.

\section{Design, policy and delivery issues}

What are the lessons from this? What are the triggers for change? What does it take to free India's children from the bondage of malnutrition? Based on the authors' own field 
Table 4 States ranked by performance of $A W C$, improvement in nutritional status of children and poverty ratio

\begin{tabular}{|c|c|c|c|c|c|c|}
\hline \multicolumn{4}{|c|}{ Children underweight (\%) } & \multicolumn{3}{|l|}{ Ranks } \\
\hline $\begin{array}{l}\text { Persons } \\
\text { below } \\
\text { poverty } \\
\text { line (\%) }\end{array}$ & NFHS-3 & NFHS-2 & $\begin{array}{l}\text { Improvement } \\
\text { (NFHS-2- } \\
\text { NFHS-3) }\end{array}$ & $\begin{array}{l}\text { Improvement } \\
\text { (NFHS-2- } \\
\text { NFHS-3) }\end{array}$ & $\begin{array}{l}\text { Performance } \\
\text { of AWC }\end{array}$ & $\begin{array}{l}\text { Poverty } \\
\text { ratio }\end{array}$ \\
\hline
\end{tabular}

States with poverty ratios higher than the national average

\begin{tabular}{|c|c|c|c|c|c|c|}
\hline Orissa & 39.9 & 44 & 54.4 & 10.4 & 1 & 3 \\
\hline Jharkhand & 34.8 & 59.2 & 54.3 & -4.9 & 15 & 9 \\
\hline Bihar & 32.5 & 58.4 & 54.3 & -4.1 & 13 & 17 \\
\hline $\begin{array}{l}\text { Madhya } \\
\text { Pradesh }\end{array}$ & 32.4 & 60.3 & 53.5 & -6.8 & 16 & 4 \\
\hline Chhattisgarh & 32 & 52.1 & 60.8 & 8.7 & 3 & 1 \\
\hline Uttar & 25.5 & 47.3 & 51.8 & 4.5 & 6 & 15 \\
\hline Maharashtra & 25.2 & 39.7 & 49.6 & 9.9 & 2 & 5 \\
\hline
\end{tabular}

States with poverty ratios lower than the national average

\begin{tabular}{|c|c|c|c|c|c|c|c|}
\hline \multicolumn{2}{|c|}{ West Bengal 20.6} & 43.5 & 48.7 & 5.2 & 5 & 7 & 10 \\
\hline Tamil & 17.8 & 33.2 & 36.7 & 3.5 & 7 & 2 & 9 \\
\hline Rajasthan & 17.5 & 44 & 50.6 & 6.6 & 4 & 13 & 8 \\
\hline Karnataka & 17.4 & 41.1 & 43.9 & 2.8 & 8 & 6 & 7 \\
\hline Assam & 15 & 40.4 & 36 & -4.4 & 14 & 14 & 6 \\
\hline Gujarat & 12.5 & 47.4 & 45.1 & -2.3 & 12 & 8 & 5 \\
\hline Kerala & 11.4 & 28.8 & 26.9 & -1.9 & 11 & 11 & 4 \\
\hline Andhra & 11.1 & 36.5 & 37.7 & 1.2 & 10 & 10 & 3 \\
\hline Haryana & 9.9 & 41.9 & 34.6 & -7.3 & 17 & 12 & 2 \\
\hline Punjab & 5.2 & 27 & 28.7 & 1.7 & 9 & 16 & 1 \\
\hline
\end{tabular}

Note Percentage of population below the poverty line in India is 21.8 per cent (2004-5).

experiences and reports of innovative and successful interventions in different parts of India and abroad, we suggest below what it will take to script a new destiny for India's children.

\subsection{Focus on children under two years}

Child malnutrition is mostly the result of inappropriate infant and young child-feeding and caring practices, and begins in the first two years of life. The current programme does not focus on children under two, when nutrition interventions can have the most impact. The focus must be on children under two.

\subsection{Outreach}

The ICDS scheme should changed from a centrebased to an outreach-based approach. An advantage of this is that the entire family is sensitised and counselled. The mitanins in Koriya district of Chhattisgarh, for example, visited each household and weighed children under five in front of their whole family. The nutritional status of the child and the significance of each grade of malnutrition were explained to the household. The mitanins counselled both parents on ways to combat malnutrition. With the involvement of the entire family, the messages were more likely to be followed. 
Diarrhoea and respiratory infections contribute to poor appetite and malnutrition. Nutrition Rehabilitation Centres should be available at Primary Health Centres for children suffering from Grade 3 or 4 malnutrition, and their mothers. AWWs should be responsible for identifying and referring such children to the rehabilitation facilities. Financial provision should be made to support families during rehabilitation. The children and their carers should be entitled to enhanced food rations under the Supplementary Nutrition Programme.

\subsection{Two-worker norm}

AWWs are overburdened and each AWC should have two AWWs, and an Anganwadi helper. The second AWW should take care of children under two and pregnant or nursing mothers, in collaboration with the village health worker, known as the ASHA (Accredited Social Health Activist). Priority should be given first to the most deprived 100 districts of India, and gradually second workers should be posted to every district.

\subsection{Improve reporting}

Most Indian states have a computerised ICDS monitoring system, but the information is not used for corrective action or analysis. Each AWC reports on the numbers of malnourished children category-wise, but these figures are neither verified independently nor used to assess the effectiveness of the programme. AWWs have too many registers to complete and are reported to be under pressure to enter 'correct', rather than accurate data. This explains why the overall percentage of malnourished children under three is under-represented as only 8 per cent (with 1 per cent of children severely malnourished), as against 46 per cent reported by NFHS-3. This reduces local accountability and ownership of the problem.

There should be greater transparency of district and centre records that should be put on a website, and there should be frequent field inspections by an independent team of experts.

\subsection{Ban packaged food for the 3-6 year age group}

This has led to massive corruption and has been justified in the name of micronutrients.

However, micronutrient supplements in the absence of adequate proteins and calories will not produce the desired outcomes. Industrially packaged foods are often rejected by children, and fed to cattle. This is the experience of 'India Mix' supplied by the World Food Programme in Rajasthan and Uttarakhand. In other states, the contract for preparing packaged foods is given to the contractor who offers the lowest tender, and then supplies cheap unpalatable products. His contract is ensured by the bribes that he offers to everyone involved.

Young children can only eat small quantities and need fat rich, energy dense food to obtain the necessary calories. In the absence of oil supplies, there is almost no fat content in the food being given, although children under three should get 40 per cent of their calorie requirement from fats. If the energy density or the amount of food per meal is low, more frequent meals may be required. India must refrain from expanding the fortification of food. Attempts must be made to satisfy children's calorie and protein needs through locally prepared food, including oil, eggs, vegetables, milk, fruits, etc. Centralised kitchens should be permitted in cities where schools have no place for cooking, but each child must get a hot cooked meal.

ICDS should learn from the success of the midday meals programme that runs fairly well even in states not known for efficiency. For children under three years, nutritious and carefully designed locally prepared take-home rations based on locally procured food should be provided. Before inviting financial bids, states must invite technical bids so that unscrupulous elements who supply packaged food through bribes are eliminated.

\section{6 Increase the involvement of panchayats/mothers' groups, etc.}

The scheme will improve when panchayats (village councils) and other community groups are involved and control the programme, including the selection of workers. Wherever the community has been involved, results have improved. In Chhattisgarh, for example, nutrition monitoring committees were formed in hamlets. These consist mainly of tribal and dalit women. The mitanins share the data on child malnutrition with the committee. This allows the community to monitor the nutritional status of children by weighing them every six months (Garg 2006). In Orissa, one study showed that women were encouraged to raise issues regarding the functioning of the $\mathrm{AWC}$, and the 
frequent absence of the AWW in the panchayat. This made the AWW more accountable to the panchayat and led to a positive impact on the performance of the AWC (WFP 2008). In many states, panchayats successfully run the midday meals programme for school children.

\subsection{Involving and promoting women}

The involvement of women, including those from marginalised communities, has a multiplier impact on outcomes. Women should be better represented among supervisors, CDPOs and other ICDS staff above the AWW level. States, such as UP, Bihar and Jharkhand have only women as Supervisors and CDPOs, however, there are many vacancies which limit their effectiveness. In Bihar, 74 per cent of the Supervisors' posts are vacant. In most states, avenues for promotion for AWWs and

Supervisors are limited, and stagnation sets in mid-career. All Supervisors should be selected from eligible AWWs, and can then be promoted.

\subsection{Improve women's mobility}

State governments should give interest-free loans to CDPOs and Supervisors to buy motorbikes, provided they have a licence. Driving courses for women staff should be provided. As a practical and long-term solution, the government should encourage school girls to learn how to ride bikes and later scooters.

\subsection{National Rural Employment Guarantee Act (NREGA)}

To increase the numbers of AWGs, 'construction of AWGs' should be added to the list of permissible works under NREGA. Additional funds could be mobilised from the Backward Regions Grant Fund. In order to improve the motivation of panchayats to use NREGA funds for this purpose, the state government might start an incentive scheme, or fix a quota out of its own contribution. These buildings should be constructed in settlements which are inhabited by currently underserved SC/ST populations.

\subsection{Grading AWCs}

GoI should introduce accreditation of AWWs, based on well-defined and transparent criteria through a consultative process by involving panchayats, mothers' committees and community groups. Some pilots have been undertaken in HP and Orissa, which recognise and reward good performance.

\subsection{Learn from international experience}

Thailand succeeded in improving child nutrition between 1980 and 1988 and reduced child malnutrition (underweight) from 50 per cent to 25 per cent. This was achieved through a mix of interventions including: intensive growth monitoring and nutrition education, strong supplementary feeding provision, iron and vitamin supplementation and salt iodisation, along with primary healthcare. High rates of coverage were ensured by human resource intensity. The programme used volunteers (one per 20 children), and involved local people. Communities were involved in needs assessment, planning, programme implementation, beneficiary selection, and seeking local financial contributions but central government controlled resource allocation, to ensure a coherent national programme.

The lessons from Thailand are relevant for India today because levels of per capita GDP, the proportion of women in the agricultural workforce and child malnutrition rates around 1980 in Thailand were similar to those in India in 2009.

\subsection{Re-examine the role of the Ministry of Women and Child Development (MUCD)}

When the MWCD was established, it was expected to take an overview of the problems of women and children, and monitor the activities of other Ministries, such as health, education, labour, drinking water and sanitation that deliver services that impinge on children's welfare. It would develop systems to inform GoI, for instance, how and why children were malnourished. Instead the Ministry confined itself to dealing with ICDS without monitoring the other inputs needed to reduce malnutrition. This defeated the purpose for which the Ministry was created. The MWCD should monitor children's access to health, water and sanitation, and how these influence malnutrition. Continuous measurement of the critical inputs will put pressure on other Ministries to improve vital services.

\section{Summing up}

The multidimensional nature of malnutrition must be reflected in ICDS implementation: food intake is only one determinant of a child's nutritional status. It is however necessary, as it attracts families to other components of the programme. In addition to supplementary feeding, state resources should be directed 
towards improving the delivery of other ICDS services. Supplementary feeding should be used strategically, as an incentive for poor and malnourished children and their mothers, so that they receive health and nutrition education interventions.

The constraints to child survival and wellbeing are rooted in bad policies, faulty project design,

\section{Notes}

1 The analysis covers the 17 major states in the country. The major states are defined as those that have a population of 20 million or more.

\section{References}

Garg, S. (2006) Chhattisgarh: Grassroot Mobilisation for Children's Nutrition Rights, Economic and Political Weekly, 26 August

Sundararaman, T. (2006) 'Universalisation of ICDS and Community Health Worker lack of appropriate $\mathrm{M} \& \mathrm{E}$, and poor governance. Action is needed on all fronts. Merely increasing the number of ICDS centres will not reduce child malnutrition. Without a major shake up in policy and an improvement in the effectiveness of its implementation, India's attainment of the MDGs looks extremely unlikely.

2 Details of the index and of the regression given later are not discussed because of constraints of space, but are available from the authors.

Programmes: Lessons from Chhattisgarh', Economic and Political Weekly, 26 August WFP (2008) The Justice of Eating, New Delhi: World Food Programme 